\title{
An Evaluation of the Combined Effect of Window Shading and Themal Mass to Reduce Overheating
}

\author{
Carlos Jimenez-Bescos ${ }^{1[0000-0003-4261-3721]}$ \\ ${ }^{1}$ Anglia Ruskin University, Chelmsford, CM1 1SQ, Uk \\ carlos.jimenezbescos@anglia.ac.uk
}

\begin{abstract}
Thermal mass has the benefit of regulating energy in buildings and generates potential savings in energy and $\mathrm{CO}_{2}$ emissions. Window and local shading can provide shelter and reduce the severity of overheating during the year and mostly during the summer period.

The aim of this study was firstly to evaluate the influence of window shading to reduce overheating and secondly to assess the thermal mass benefits in the presence of shading devices to alleviate the impact of overheating.

This study was based on dynamic thermal simulations to analyse the performance of different window and local shading devices to avoid overheating. Twenty building simulation models were performed using the Energyplus plugin in DesignBuilder to evaluate the effect on the thermal mass behaviour to mitigate overheating according to different window shading devices.

This study confirmed, as expected, that the use of window shading helps to alleviate the overheating hours in the test room and as such, improving the thermal comfort and reducing the need for cooling. Furthermore, when the window shading devices are coupling with thermal mass and night ventilation, the reduction on overheating hours achieved will reach a reduction of over $50 \%$ with respect to not exposing the thermal mass. In conclusion, exposing the thermal mass coupled with a night ventilation strategy provides a reduction on overheating hours, which is increased by using different window shading devices. Exposure of the thermal mass provides a good strategy for reducing the need for cooling and increasing thermal comfort.
\end{abstract}

Keywords: Window Shading, Overheating, Dynamic Simulation, Thermal Mass.

\section{Introduction}

Overheating issues are becoming more common nowadays in the built environment as a consequence of the effect of climate change, the use of thermal mass presents a good opportunity for non-domestic buildings to regulate the indoor environment, while saving energy and CO2 emissions. The literature $[1,2]$ has presented the benefits available by the use of thermal mass and furthermore, when coupled together with night ventilation. According to the Zero Carbon Home [3], combining the effects of thermal mass and night purge ventilation create benefits to reduce overheating. In 
non-domestic buildings, the thermal mass tends to be hidden behind a false ceiling mainly for acoustic reasons. The suspended ceiling, made of compressed mineral wool tiles, generates a negative effect on the use of the thermal mass, restricting the use of the thermal mass to regulate the internal conditions by loading (day) and unloading (night) itself. By making use of the thermal benefits to regulate the indoor thermal comfort, overheating in summer can be reduced and the need for cooling minimised, allowing a reduction in energy consumption and the respective $\mathrm{CO} 2$ emissions savings [4].

Furthermore to the use of thermal mass coupled with night ventilation, shading should be use to control and reduce solar gains through glazing helping to reduce overheating issues by excluding or minimizing the effect of solar radiation in the indoor environment [5, 6, 7]. The importance of adequate shading is even more relevant in well insulated buildings, in which overheating issues are happening during the summer months [8].

Regarding provision of shading, several options are available:

- Window shading by blinds, which could be internal, external or midpane [5].

- Use of electrochromatic glazing for window shading [5].

- Integrating overhangs into the design to provide local shading [3]

The aim of this study was firstly to evaluate the influence of window and local shading to reduce overheating and secondly to assess the benefits of using thermal mass in conjunction with the shading devices to alleviate the impact of overheating.

\section{$2 \quad$ Method}

The methodology in this paper is a continuation research building on previous work by the author $[4,9]$

An exemplar test room, as shown in Fig. 1, was modeled with dimensions $7.5 \mathrm{~m} \mathrm{x}$ $7.5 \mathrm{~m} \times 3.5 \mathrm{~m}$. The test room was dynamically simulated using energyplus in DesignBuilder software. U-values for internal floors hidden (with suspended ceiling) were $0.739 \mathrm{~W} / \mathrm{m} 2 \mathrm{~K}$ and exposing (without suspended ceiling) the thermal mass were 1.523 $\mathrm{W} / \mathrm{m} 2 \mathrm{~K}$ as previously published [4]. The test room was naturally ventilated and a night cooling ventilation strategy was used to cool down the thermal mass and discharge the heat accumulated during the day in accordance to the conditions presented below. No cooling was used in the simulations to be able to isolate and specifically quantify the benefits provided by the thermal mass to reduce overheating on its own. The simulated test room results were audited to confirm corroboration of results with building physics principles. 


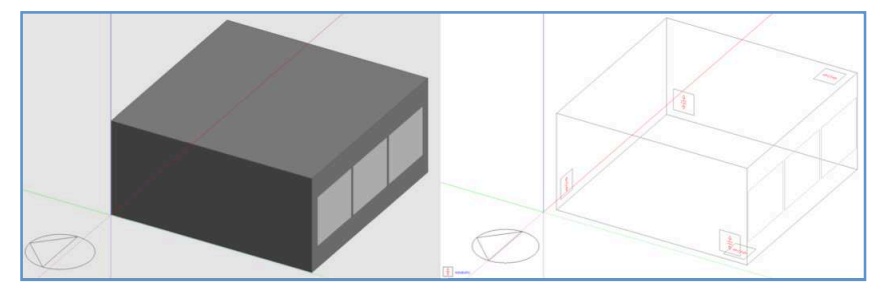

Fig. 1. Test room for dynamic building simulation.

The dynamic computational simulation in DesignBuilder had the following parameters:

- Simulated location in London (Islington).

- Medium weight construction according to Part L2 2010 (UK).

- All surfaces adiabatic apart from south wall being external with a U-value of $0.26 \mathrm{~W} / \mathrm{m}^{2} \mathrm{~K}$.

- $50 \%$ glazing in south wall with a $\mathrm{U}$-value of $1.978 \mathrm{~W} / \mathrm{m}^{2} \mathrm{~K}$ and g-value of 0.687 .

- Office equipment load of $10 \mathrm{~W} / \mathrm{m}^{2}$.

- Lighting load of $0 \mathrm{~W} / \mathrm{m}^{2}$ to focus on the performance of the thermal mass.

- People density of 0.111 people $/ \mathrm{m}^{2}$, following an occupancy schedule from 9:00 to $17: 00$

- Constant infiltration of 0.5 air changes per hour (ACH).

- Natural ventilation rate of 1.5 ACH, following a schedule from 8:00 to 19:00

- Night ventilation rates of $6 \mathrm{ACH}$, following a schedule from 24:00 to 6:00

- Heating by gas boiler.

- Heating setpoint temperature of $20^{\circ} \mathrm{C}$ and set back temperature of $12^{\circ} \mathrm{C}$.

- No active cooling.

- Simulations run for one year (8760 hours).

The following window and local shading devices were simulated with and without suspended ceiling to compare the effect on overheating hours:

- No shading

- Window shading (implemented according to office occupancy schedule by the UK's National Calculation Method for Non Domestic Buildings)

- Inside blind with high reflective slats

- Outside blind with high reflective slats

- Midpane blind with medium reflective slats

- Inside shade roll light translucent

- Inside shade roll light opaque

- Electrochromatic reflective $6 \mathrm{~mm}$ glazing

- Electrochromatic absortivetive $6 \mathrm{~mm}$ glazing

- Local shading

○ $\quad 0.5$ meter overhang.

○ 1 meter overhang. 
The overheating limit was set to $28^{\circ} \mathrm{C}$ in accordance with CIBSE definitions [10, $11]$.

\section{$3 \quad$ Results}

Twenty dynamic building simulations were solved using the dynamic Energyplus engine in DesignBuilder to assess the overheating performance, with and without the suspended ceiling, of a range of window and local shading devices. The simulations were modelled without the inclusion of cooling to control overheating, as the main purpose of the simulations were to evaluate the benefits of coupling the thermal mass and purge night ventilation. Two simulations were performed with the test room for each window and local shading device, one simulating the effect suspended ceiling and the other one exposing the thermal mass by non-suspended ceiling.

As previously presented in the literature for London (Islington) [4], the simulations were evaluated following a temperature distribution approach to allocate the number of hours below, at and above every temperature value in the model. The results show the range of temperature distribution with and without suspending ceiling and taking advantage of the thermal mass and purge night ventilation. Table 1 shows the total number of overheating hours above $28^{\circ} \mathrm{C}$, the overheating hours are shown for each window and local shading device and a case of no shading, with suspended ceiling and using the thermal mass and ventilation (non suspended ceiling).

Table 1. Overheating hours over $28^{\circ} \mathrm{C}$ for non-suspended ceilings (thermal mass exposed) and suspended ceilings from simulation results.

\begin{tabular}{|c|c|c|}
\hline Shading type & $\begin{array}{c}\text { Non-Suspended } \\
\text { ceiling [hours] }\end{array}$ & $\begin{array}{c}\text { Suspended ceiling } \\
\text { [hours] }\end{array}$ \\
\hline No Shading & 533 & 730.5 \\
\hline Inside Blind & 83 & 229 \\
\hline Outside Blind & 5 & 14.5 \\
\hline MidPane Blind & 161.5 & 334 \\
\hline $\begin{array}{c}\text { Inside Shade Roll } \\
\text { Translucent }\end{array}$ & 112 & 302.5 \\
\hline $\begin{array}{c}\text { Inside Shade Roll } \\
\text { Opaque }\end{array}$ & 56.5 & 171.5 \\
\hline $\begin{array}{c}\text { Electrochromic } \\
\text { Reflective }\end{array}$ & 7 & 30 \\
\hline $\begin{array}{c}\text { Electrochromic } \\
\text { Absorbtive }\end{array}$ & 7 & 39 \\
\hline 0.5m Overhang & 189 & 387 \\
\hline 1m Overhang & 42 & 56 \\
\hline
\end{tabular}


Fig 2. presents a comparison of percentage reduction on overheating hours over $28^{\circ} \mathrm{C}$ due to the influence of window shading versus no shading for a suspended ceiling and non-suspended ceiling scenario. The percentage is calculated from the baseline of no shading at all to the reduction in overheating hours above $28^{\circ} \mathrm{C}$ due to the use of window and local shading devices as presented in Table 1. Very high overheating reductions, close to $100 \%$, can be achieved by using electrochromatic glazing or outside blinds, while the smallest reductions are achieved by the use of midpane blinds and a 0.5 meter overhang. Regardless being the smallest reduction, they still achieve reduction around 50\%. It must be noted that in all cases, the use of the thermal mass provided a bigger reduction in overheating, much more pronounced with the use of internal and midpane blinds, as well as shade rolls.

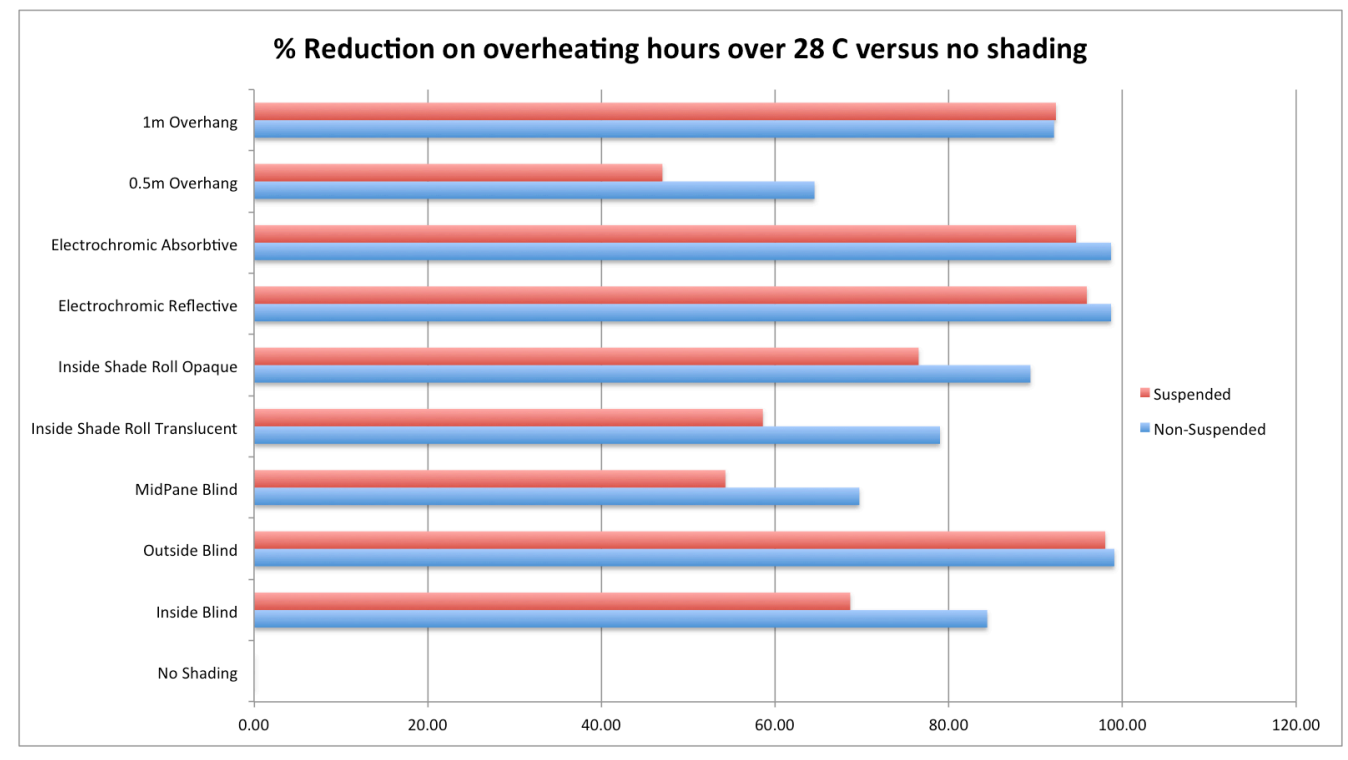

Fig. 2. Comparison of percentage reduction on overheating hours over $28^{\circ} \mathrm{C}$ by window and local shading versus no shading for suspended ceiling and non-suspended ceiling scenario.

Fig. 3 presents the percentage reduction on overheating hours over $28^{\circ} \mathrm{C}$ due to exposing the thermal mass in non-suspended ceilings. This percentage reduction is calculate based on the overheating hours above $28^{\circ} \mathrm{C}$ when having a suspended ceiling and the overheating hours resulting from exposing the thermal mass (non-suspended ceiling) for each window and local shading devices as presented in Table 1. Overheating reductions above $70 \%$ can be achieved by using electrochromatic glazing, while the use of blinds and rolls allow reductions above $60 \%$. Little benefit is appreciated by the use of a 1 meter overhang but this is due to the overhang already providing a massive reduction of overheating hours by blocking the solar radiation from reaching the glazing, so minimising any radiation effect in the inside room which would be charging the thermal mass and overheating hours being mostly driv- 
ing by internal gains, form people and equipment. In the case of the smaller contribution of exposing the thermal mass for the case of "no shading", the issue for the thermal mass is completely the opposite. In this case, the thermal mass is fully loaded early in the day, as the number of overheating hours are above 700 hours a year. When the thermal mass is fully loaded, it will have no benefit for reduction until the heat contained in the thermal mass is discharged with the night ventilation strategy.

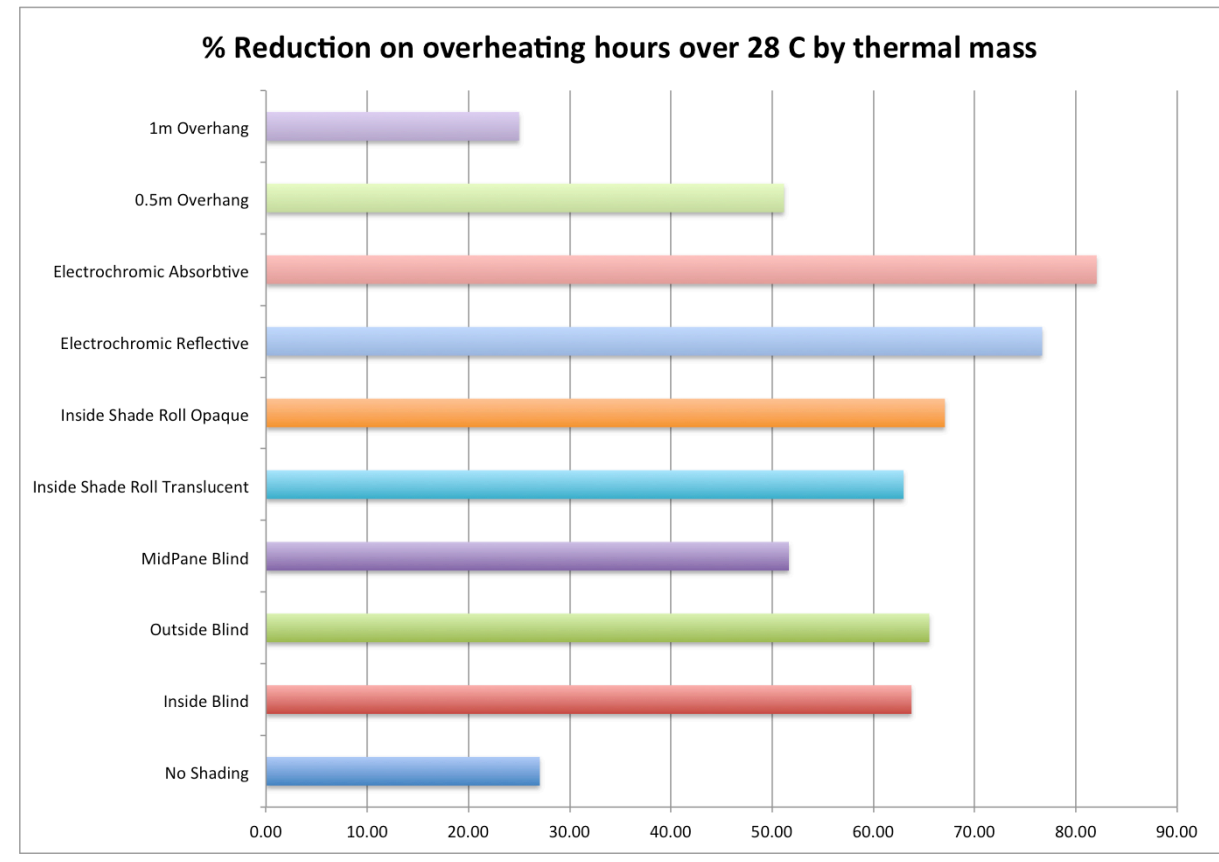

Fig. 3. Percentage reduction on overheating hours over $28^{\circ} \mathrm{C}$ by using thermal mass (nonsuspended ceiling) versus a suspended ceiling scenario.

\section{Discussion}

The use of window or local shading devices to control the solar gain transmission in window can greatly contribute to a reduction of overheating hours over $28^{\circ} \mathrm{C}$ as supported by this study and the literature $[5,6,7]$. As expected, external or outside blinds provide one of the highest overheating reductions, which agree with the literature $[3,5,8]$. A design limitation on the use of external or outside window shading devices in the United Kingdom is the practice of installing windows, which open outward [3, 12]. On the one hand, electrochromatic glazing provides high overheating reductions, similar to the use of external blind, but avoiding the limitation on opening outwards. On the other hand, electrochromatic glazing has the highest economic cost in terms of new build and retrofit [5], making it the least likely option for window shading regardless of the very good performance. 
On top of the benefits achieved by using the window and local shading devices, removing the suspended ceiling will allow the thermal mass to be available in nondomestic buildings to provide further overheating reductions and minimise further the number of overheating hours above $28^{\circ} \mathrm{C}$. This effect is achieved in all window and local shading device simulations for London (Islington), when comparing the overheating hours for the test room with suspended ceiling, blocking the thermal mass, and with non suspended ceiling. The results presented in this paper agree with previous work reporting the advantages of allowing the thermal mass to be used, while coupling with shading devices and purge night ventilation $[1,2,5,6,7,12]$.

The use of cooling in non-domestic building correlated with the number of overheating hours taking place. Cooling will increase the building energy use and the correspondent carbon emissions to regulate the indoor thermal comfort. An increase of overheating hours will drive upward the cooling demand and as such, a higher energy use for the cooling equipment, which will be reflected on higher carbon emissions for the building.

While this study supports the use of thermal mass and purge ventilation as a mechanism to avoid overheating $[1,2,3]$ on its own, the benefits of thermal mass can be further extended when window shading devices and local shading is used to limit the solar transmission through glazing $[5,6,7]$.

These results should be taken into account in the design of new buildings and refurbishment work to avoid overheating and to provide mitigating options to deal with overheating. This study highlights the importance of the thermal mass performance, night ventilation and its effect to reduce overheating also when window shading or local shading is impemented to limit and reduce overheating.

\section{Conclusion}

This study confirmed, as expected, that the use of window shading helps to alleviate the overheating hours in the test room and as such, improving the thermal comfort and reducing the need for cooling. Furthermore, when the window shading devices are coupling with an optimised used of the thermal mass and night ventilation, the reduction on overheating hours achieved will reach a reduction of over $50 \%$ with respect to not exposing the thermal mass. In conclusion, exposing the thermal mass coupled with a night ventilation strategy provides a reduction on overheating hours, which is increased by using different window shading devices. Exposure of the thermal mass provides a good strategy for reducing the need for cooling and increasing thermal comfort

\section{References}

1. Energy Saving Trust. CE129 Reducing overheating - a designer guide (2005).

2. Building Research Establishment (BRE). Thermal mass and overheating (2005).

3. Zero Carbon Home. Understanding overheating - where to start: An introduction for house builders and designers. NHBC Foundation (2012). 
4. Jimenez-Bescos, C.: The effect of suspended ceilings on thermal mass to reduce overheating. In: Proceedings of CISBAT 2015, vol II, 821-826. ISBN 978-2-9701052-2-0, Lausanne (2015).

5. Zero Carbon Home. Solutions to overheating in homes (2016).

6. Department of Energy and Climate Change. Guidance on preventing overheating in the home (2015).

7. Adaptation and Resilience in a Changing Climate Coordination Network. Overheating in homes - Advice and evidence from the latest research (2013).

8. Morten, W.: Strategies for mitigating the risk of overheating in current and future climate scenarios. Encraft Technical Insight (2015)

9. Jimenez-Bescos, C.: An evaluation on the effect of night ventilation on themal mass to reduce overheating in future climate scenarios. Energy Procedia 122, 1045-1050 (2017).

10. CIBSE. TM52: The limits of thermal comfort: Avoiding overheating in European buildings. (2013).

11. CIBSE. Guide A: Environmental design. (2015).

12. Dengel, A., Ormandy, D., Ezratty, V.: Guidance document: Overheating in dwellings, Building Research Establishment (BRE) (2016).

13. Artmann N, Manz H, Heiselberg P. Parameter study on performance of building cooling by night-time ventilation. Renewable Energy 33, 2589-2598 (2008) 